\title{
Effect of Vapor Diffusion Port on Drying of Wood-Frame Walls
}

\author{
Ben Zegen Reich ${ }^{1}$, Hua Ge ${ }^{1}$ and Jieying Wang ${ }^{2}$ \\ ${ }^{1}$ Department of Building, Civil and Environmental Engineering, Concordia University, Montreal, \\ Canada,hua.ge@concordia.ca \\ ${ }^{2}$ FPInnovations, 2665 East Mall, Vancouver V6T 1Z4, Canada, Jieying.Wang@fpinnovations.ca
}

\begin{abstract}
Vapor diffusion ports (VDP) that are drilled in the exterior sheathing of wood-frame walls are commonly used in wood-frame construction in the coastal region of British Columbia with the intention to improve the drying capacity of wood-frame exterior walls. This practice was originated following the systematic building envelope failures due to rain penetration that occurred in this region around 1985-1995. A previous laboratory study carried out by FPInnovations found that the diffusion ports provided substantial improvement in the drying rates of Oriented Strand Board (OSB) sheathed walls, but not for plywood sheathed walls (Hazleden and Morris, 2001). A more recent laboratory test (Wang, 2018) using wood-frame walls with higher insulation levels in compliance with the current more stringent energy code found that VDPs did not significantly improve the drying rates; On the other hand, the provision of VDPs may allow moisture ingress into the wall assembly instead in a damp environment. The difference in these two studies in terms of test wall sizes, moisture sources, and test conditions may have attributed to the different findings. To provide a more comprehensive and systematic evaluation of the effect of VDPs, hygrothermal simulations using Wufi-2D are carried out in this study. The Wufi-2D model is firstly validated by comparing simulation results to the test results provided by Wang (2018), which tested the effect of VDPs under laboratory conditions by using a wetted wood block installed inside each wall assembly as a simulated moisture source. The simulation results agree well with the measurements. The Model is then used for sensitivity analysis with different levels of rain leakage with and without VDPs using yearly weather data. The variables included are types of exterior insulation, types of sheathing (OSB versus Plywood), and types of sheathing membrane. This paper presents the validation of the model and simulation results under transient conditions with rain leakage. General conclusions on the effect of VDPs are provided.
\end{abstract}

Keywords: Vapor Diffusion Ports, Wood-Frame Walls, Hygrothermal Simulations, Durability.

\section{Introduction}

Moisture content (MC) of various elements of a building's wall assembly greatly influences its durability. In areas with high seasonal wetting potential such as the coastal region of British Columbia (BC), a practice of providing vapor diffusion ports (VDP) in the exterior sheathing of wood-frame exterior walls to encourage drying was introduced in the late 1990's and gained popularity in the region. However, little research has been done to investigate the effect of VDPs on building assembly durability. There are mainly two laboratory experiments. Hazleden and Morris (2001) compared drying rates of larger wood-frame assemblies with framing wetted to high level of moisture contents initially using a large environmental chamber under laboratory conditions with the addition of VDPs. The moisture contents of sheathing were measured. It was found that for OSB sheathed walls, VDPs had a substantial effect on drying of sheathing, with typical MC levels in the sheathing being 34\%-36\% MC without a VDP and $22 \%-25 \%$ MC with a VDP after the drying process. For plywood sheathed walls, VDPs had 
very little effect on drying performance. Wang (2018) tested the VDPs applied on more recent but smaller wall assemblies and materials, including deep cavity walls and exterior insulated assemblies under laboratory conditions. The moisture contents of an initially wetted wood blocked placed over the bottom plate were measured. The study concluded that VDPs had insignificant effects on drying of the wet wood block simulating a rain leakage scenario for assemblies sheathed in OSB or plywood.

These two previous studies focused on laboratory testing under simulated environmental conditions. This study aims to provide a more comprehensive and systematic evaluation of the effect of VDPs through transient hygrothermal simulations representing more realistic climatic weather conditions and moisture loads.

\section{Methodology}

The program chosen for hygrothermal simulation is Wufi-2D, a transient $2 \mathrm{D}$ heat and mass transfer program that is capable of simulating the effect of VDPs on the hygrothermal performance of the wall assemblies. The model is firstly validated by comparing simulation results with the measurements from the recent experiment conducted by Wang (2018) under laboratory conditions. The validated model is then used to evaluate the effect of VDP on the hygrothermal performance of a typical $2 \times 6$ wood-frame wall, defined as a baseline wall, under real weather conditions with rain leakage assumed to the exterior surface of sheathing as a moisture source. A parametric study is carried out on the baseline wall to investigate the effect

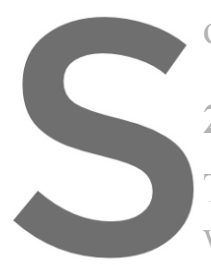
of various parameters

\subsection{Hygrothermal Model Setu}
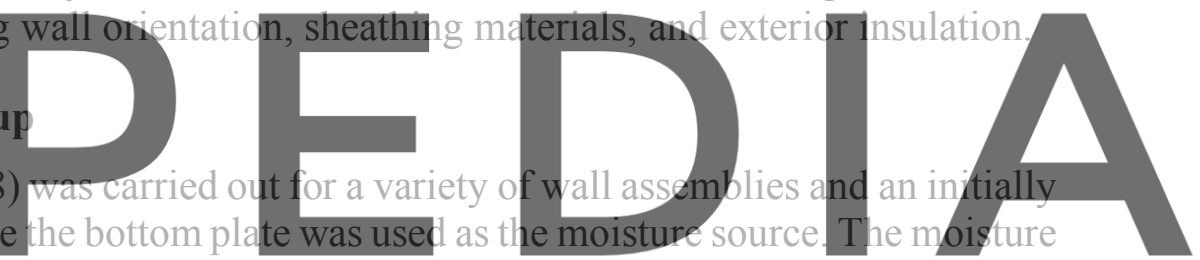

content of the wet wood block was measured during the drying process at two depths, $5 \mathrm{~mm}$

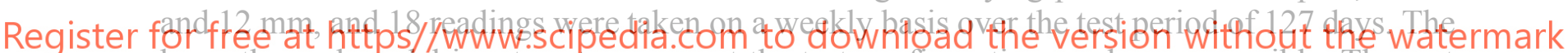
hygrothermal model is set up to represent the test configuration as close as possible. The wet wood block is divided into two layers, surface and center, for a better comparison of measurements at two depths. The VDP has a diameter of $50 \mathrm{~mm}$ and placed $100 \mathrm{~mm}$ above the wet wood block. The VDP is represented by a $50 \mathrm{~mm}$ slot in the hygrothermal model. The initial $\mathrm{MC}$ of each layer is set to match the experiment readings on day 0 , which vary among test assemblies. The experiment was conducted in an outside shed that was open to the environment but covered from solar radiation and rain events, and the simulation model uses temperature and relative humidity $(\mathrm{RH})$ data measured on-site but no rain or solar inputs. Figure 1 shows the simulation model in Wufi-2D and the experiment test setup. 


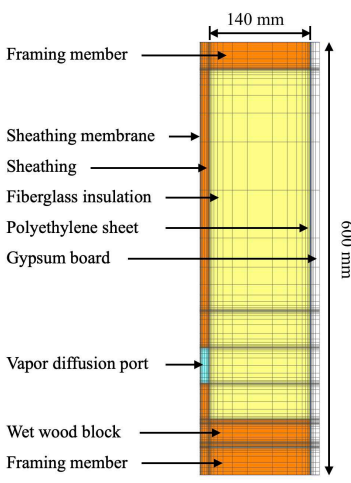

(a)

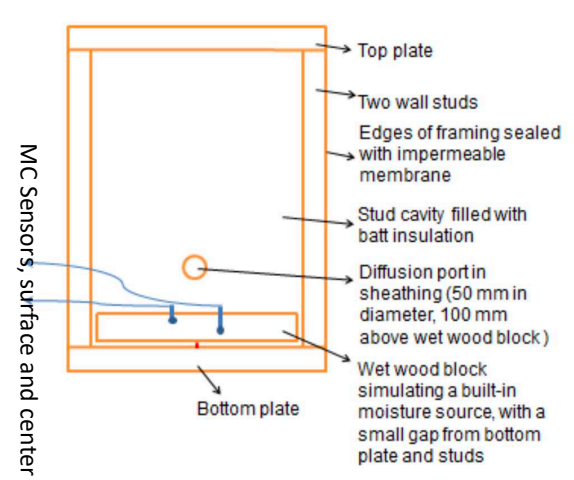

(b)

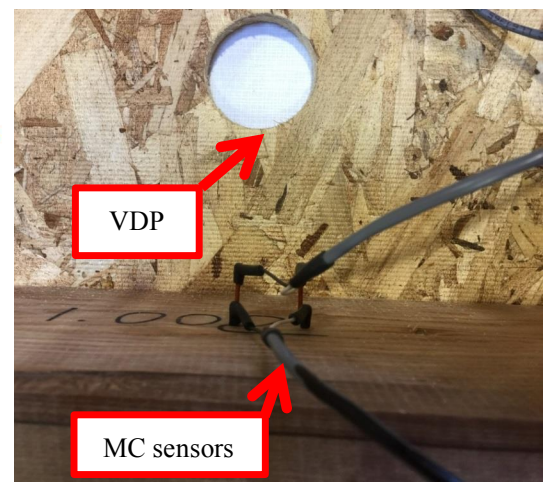

(c)

Figure 1. (a) Wufi-2D simulation model for validation (b, c) Experiment assembly (Wang, 2018).

\subsection{Hygrothermal Model Validation}

Sixteen of these wall assemblies are simulated, with OSB and plywood sheathing, with and without exterior insulation, with and without VDPs, and the MC of the wet wood block from the simulations are compared to the experiment results. As an example, Figure 2 shows the comparison between experimental and simulation results for the case of an OSB sheathed 2x6 wall with no VDP and the case of OSB sheathed wall with VDP. In general, the simulation results agree well with the measurements. The simulation results have a better agreement with the measurements for the occurs during the initial drying period. This may set in the model as only two measurements, at 5 n model's limited capacity in modeling moisture transport in wood at moisture co above its fiber saturation. The comparison between the simulation and experinent results is made by root-mean-square error (RMSE), which is the root of the sum of the differences

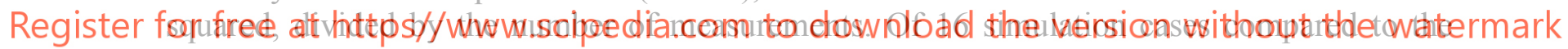
experiment, the RMSE ranges from 0.81 to 3.77 with a median value of 1.65 for the surface layer, and ranges from 0.38 to 4.72 with a median value of 1.30 for the center layer.

(a)

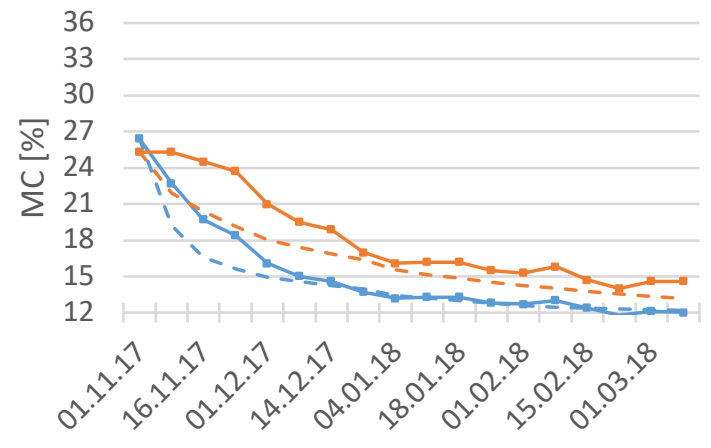

Date

—. Experiment $5 \mathrm{~mm}$

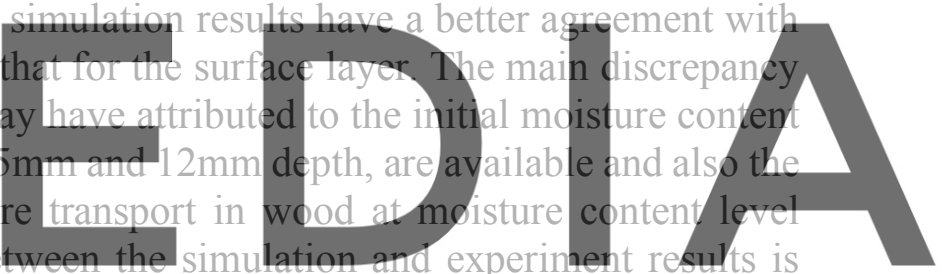

(b)

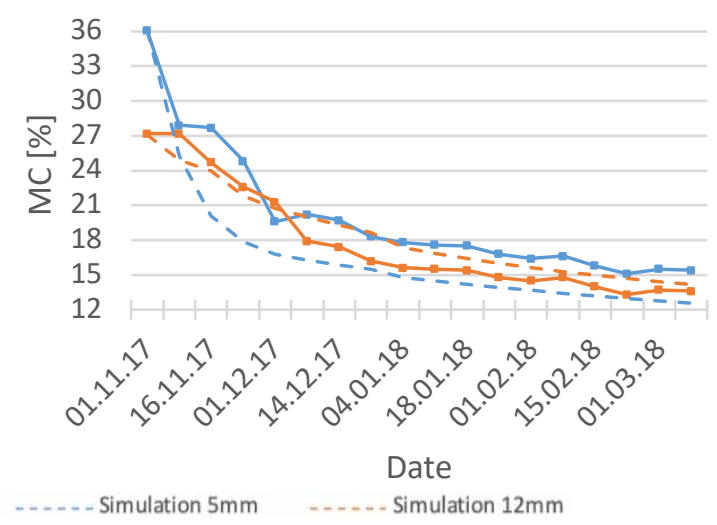

Figure 2. MC of wet wood block for an OSB sheathed $2 \times 6$ wall with no exterior insulation, surface and center layers, experiment and simulation results, without (a) and with (b) VDP. 


\subsection{Parametric Study}

The baseline assembly is a $140 \mathrm{~mm}$ deep and $600 \mathrm{~mm}$ high wall cavity filled with fiber glass insulation, a polyethylene vapor barrier and gypsum board towards the interior, sheathed in OSB and protected with a spun bonded-polyolefin (SBPO) membrane. Cladding assumed is a $13 \mathrm{~mm}$ fiber cement layer with a $20 \mathrm{~mm}$ ventilated air space behind it with a 100 air changes per hour to the exterior air assumed. To evaluate the role of VDPs under more realistic conditions, the validated model is adapted with the removal of the wet wood block and the addition of rain penetration to the sheathing as an ongoing moisture source, aligned with the ASHRAE 160 standard. 1\% fraction of driving rain is applied uniformly on the sheathing material. The initial MC of the sheathing and framing is set to $10 \%$.

The weather data used is for Vancouver, BC. The baseline weather data corresponds to the most severe year concerning moisture damage to building envelopes out of a measured period of 10 years, as published in ASHRAE RP-1325 by Salonvaara, Zhang, and Karagiozis (2011). Orientation is East, the prevailing wind-driven rain direction. The rain model used is for buildings up to 10 meters in height. Interior conditions are set using ASHRAE-160 model, heating only. The simulation time period is two years, starting November 1st, 2017 at 1-hour intervals.

Following the baseline simulations, the effect of wall orientation is investigated by facing the wall to south instead of east for the maximum solar exposure instead of maximum rain deposition. Plywood sheathing is simulated to compare with the OSB baseline. Mineral wool
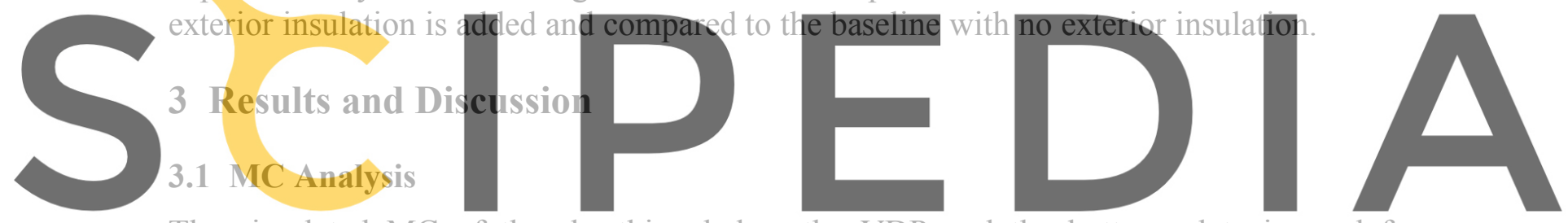

The simulated MC of the sheathing below the VDP and the bottom plate is used for a Register formparisan Rtepssephlieswithandivithomt todof

\subsubsection{Baseline case}

3.1.1.1 Sheathing Figure 3 presents the MC of the OSB sheathing below the VDP and of the bottom plate for the baseline simulations. The simulation begins Nov. 1st, the beginning of the winter which is the rainy season in Vancouver, and so in the beginning of the simulation there is quick intake of $\mathrm{MC}$ from the environment and rain penetration. The moisture intake is slightly more rapid for the assembly with a VDP by a maximum difference of $0.63 \% \mathrm{MC}$ that happens on Nov. 11th. Both assemblies reach a similar maximum $\mathrm{MC}$ after the first winter, with the VDP assembly reaching $27.5 \% \mathrm{MC}$ on Feb. 28th and the assembly without the port reaching $28.3 \% \mathrm{MC}$ on the same day. On following winters, when the starting MC is higher, the VDP assembly reaches $28.8 \% \mathrm{MC}$ and the assembly without the port reaches $30.4 \% \mathrm{MC}$, also on Feb. 28th. Thus, the maximum MC value for the assembly without a VDP is $1.6 \%$ higher than that with VDP.

From beginning of the spring until end of the summer (beginning of Mar. until end of Aug.), the assemblies dry out to the exterior, and the assembly with the VDP has MC by up to $3.8 \%$ lower than the assembly without VDP at times. 


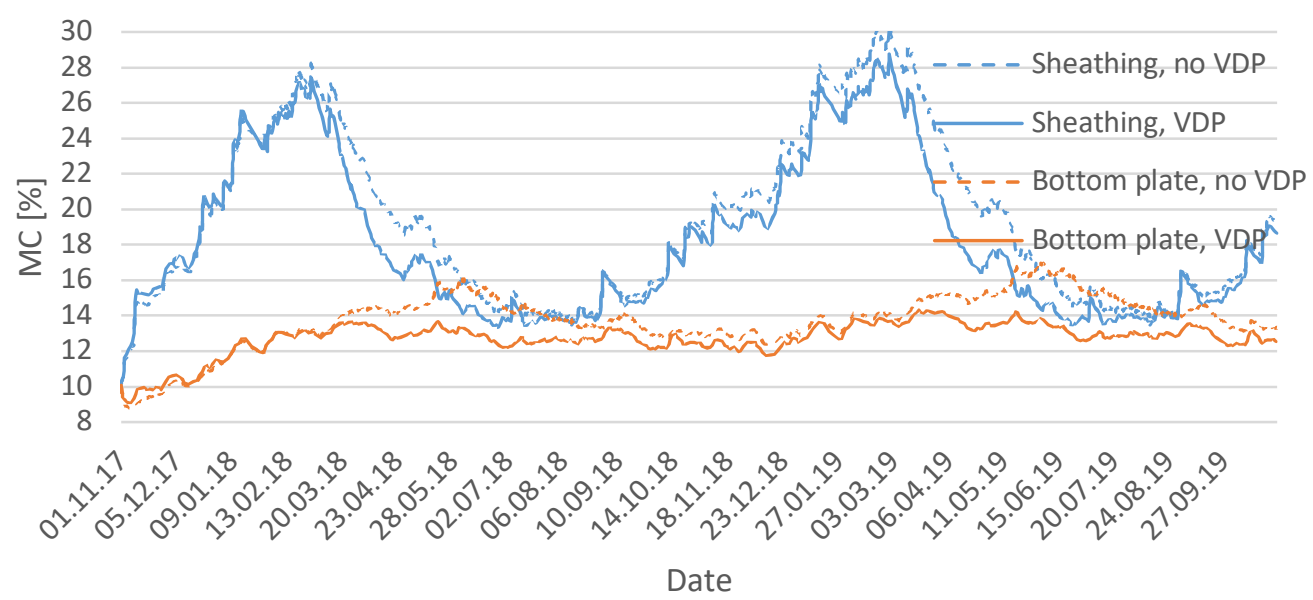

Figure 3. MC of OSB sheathing and bottom plate for the baseline rain infiltration simulations.

The time to dry from the maximum MC to under $20 \% \mathrm{MC}$ is 34 days for the VDP assembly, occurring on April 4th, compared to 56 days for the assembly with no port, occurring on April 26th. The autumn period (Sep. to Nov.) is similar to the winter period with slightly decreased wetting.

Other than the beginning of the first winter, the assembly with the VDP has a lower value of

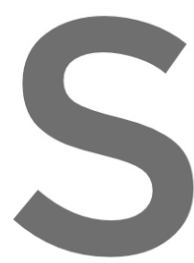

$\mathrm{MC}$ for the rest of the s.

and without VDP is sim

environment due to the

3.1.1.2 Bottom plate. In

wall assembly that are furthe
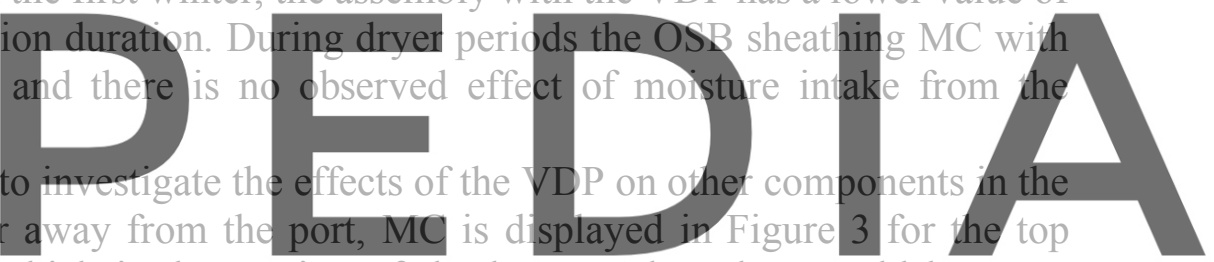

$5.3 \mathrm{~mm}$ of the bottom plate, which is the portion of the bottom plate that would be more

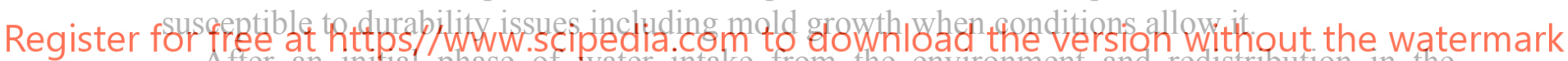
After an initial phase of water intake from the environment and redistribution in the

assembly, the bottom plate shows a relatively low variance in MC values throughout the year.

During periods of wetting, which occurs to the sheathing, there is little difference between the MC with and without the VDP. Contrarily, during drying periods, the MC of the bottom plate for assemblies with a VDP is by up to $3.3 \%$ lower. This can be explained by the quick redistribution process within the assembly, which makes the MC difference in the bottom plate follow the MC difference in the sheathing.

For the bottom plate, similar to the sheathing, no undesired effects of the VDP are observed, except for the beginning portion of the simulation where the VDP allows for quicker moisture intake. Overall, it is found that the MC of other components in the assembly follows closely the differences in $\mathrm{MC}$ in the sheathing.

\subsubsection{Effect of wall orientation}

Two assemblies with the same parameters but facing south instead of east for maximum solar exposure instead of maximum rain deposition are simulated. Figure 4 presents these results compared to the baseline. Due to the lower rain exposure on south orientation, the MC values of sheathing are significantly lower, with a maximum value of below $20 \% \mathrm{MC}$ as opposed to a 


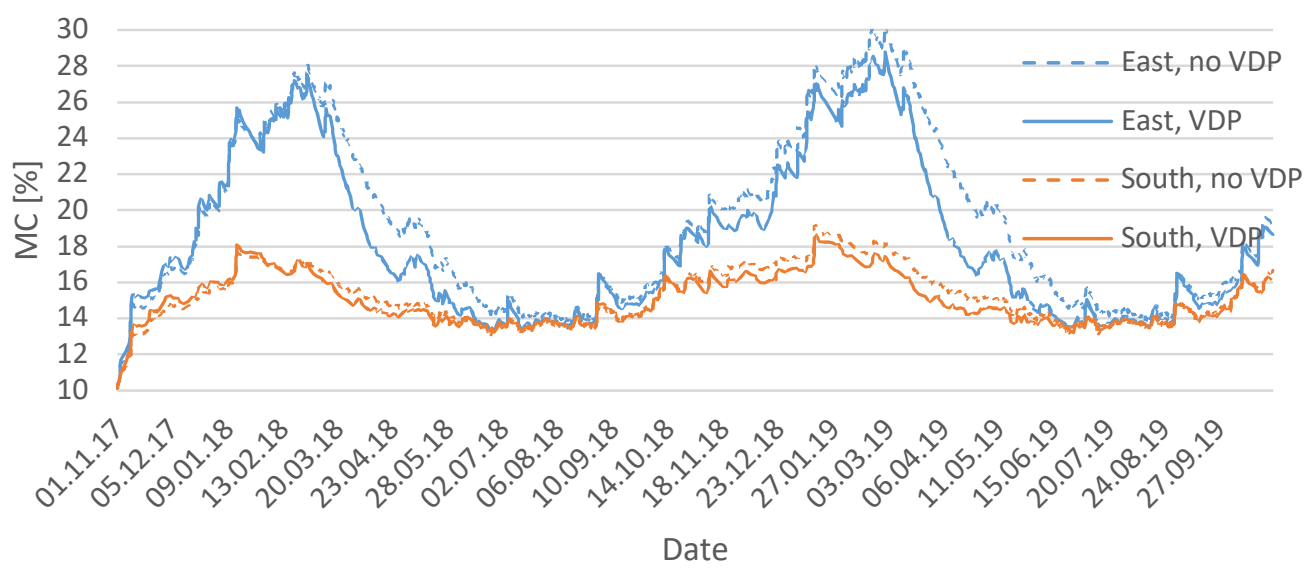

Figure 4. sheathing MC for east and south orientations, with and without a VDP.

value of $30 \% \mathrm{MC}$ for the baseline simulation facing East. The effect of the orientation change is significant because it directly affects the amount of driving rain that is deposed on the sheathing. The VDP assembly compared to the one without shows a more moderate improvement of 1\% lower MC facing south compared to 3.8\% facing east at most. Same as with the baseline simulations, there are no adverse VDP effects except for a faster moisture intake during the first transient phase of moisture equilibration in the beginning of the simulation.

3.1.3 Effect of sheathing materiats

Figure 5 shows the comparisan in MC between plywoon similar to the OSB assemblies, as are drying times to reach under $20 \% \mathrm{MC}$. The maximum difference between values with and without a VDP is 4.8\% MC for plywood compared to 3.8\%

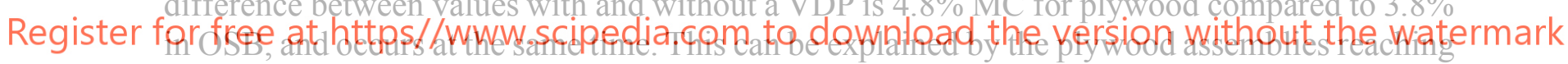
higher $\mathrm{MC}$ values and being able to dry further than the OSB assemblies, with or without the presence of a VDP. It shows that for high load of wetting, VDPs can be beneficial in piywood too.

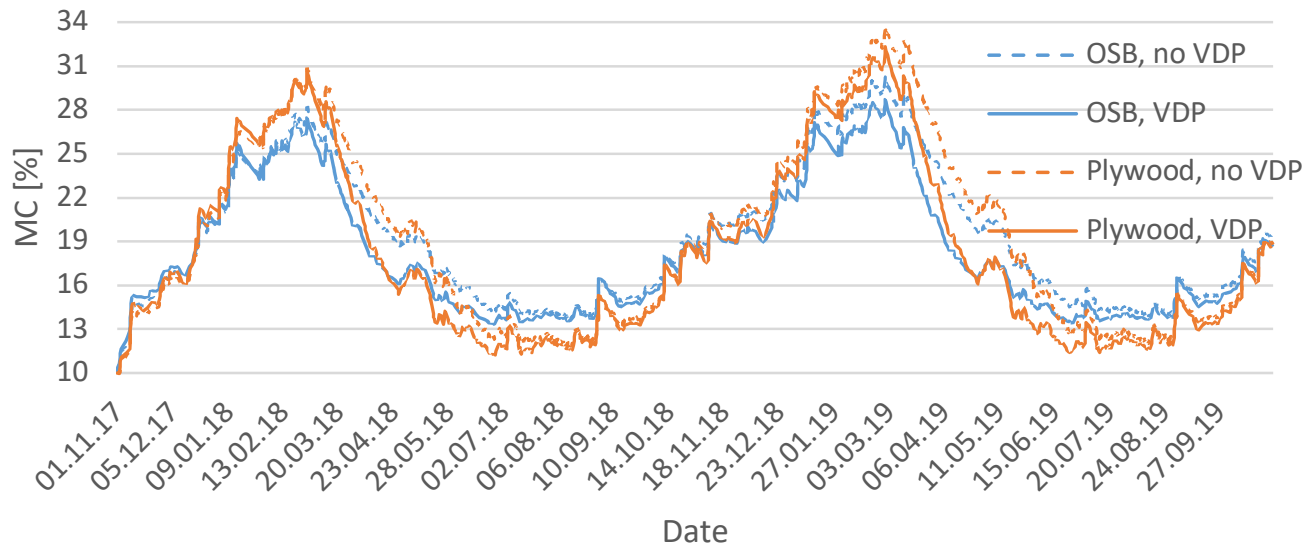

Figure 5. MC in sheathing (OSB vs. plywood), east orientation, with and without a VDP. 


\subsubsection{Effect of adding exterior insulation}

An exterior insulation layer of $75 \mathrm{~mm}$ mineral wool is added to the baseline assembly. Figure 6 presents the sheathing MC for the assemblies with and without mineral wool exterior insulation, with and without a VDP. MC is significantly lowered and so the VDP effect is reduced. The $\mathrm{MC}$ behavior stays similar to the baseline simulation. For the baseline simulation with no VDP compared to the assembly with mineral wool exterior insulation and no VDP, the maximum MC is reduced by $7.5 \%$, from $30.5 \%$ to $23 \%$, while the minimum MC values do not change. The VDP maximal effect is reduced from maximum relative drying of $3.8 \%$ to $2.2 \%$ $\mathrm{MC}$, and there is no moisture intake from the environment.

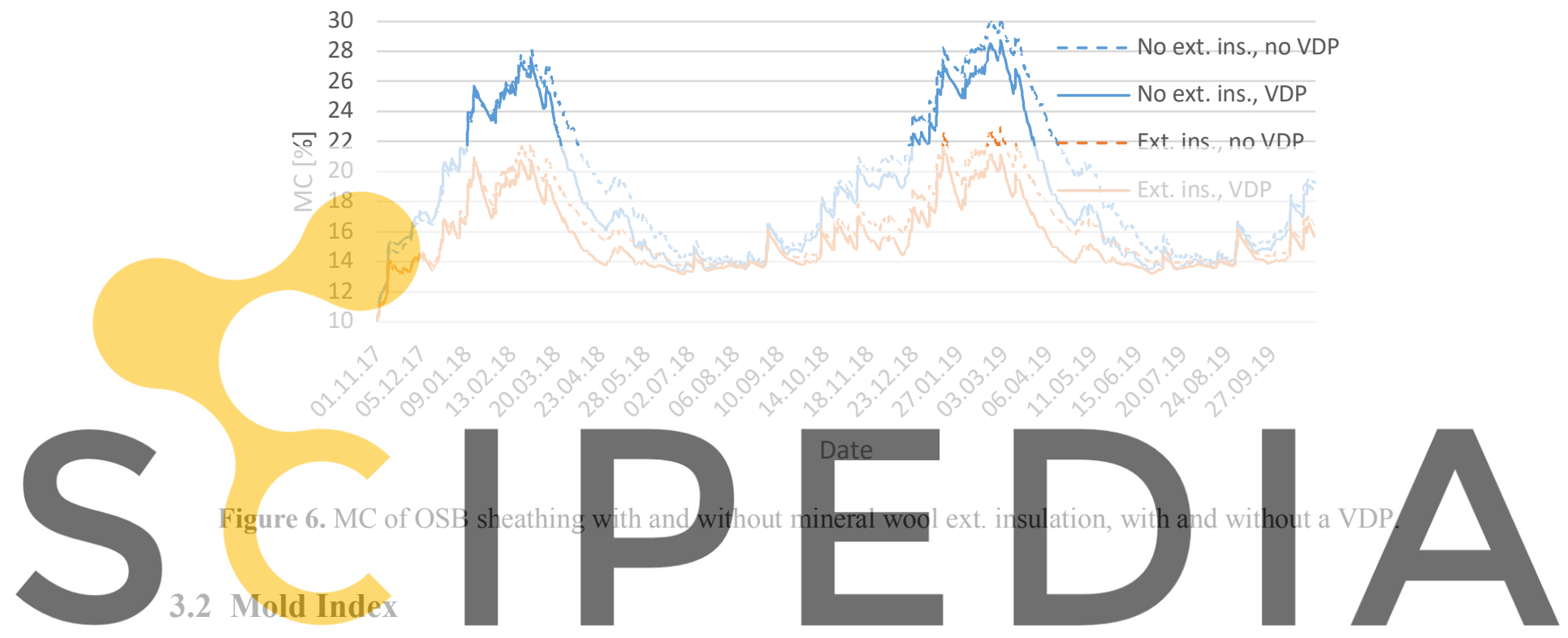

In addition to the examination of resulting MC in the assembly, mold index is calculated

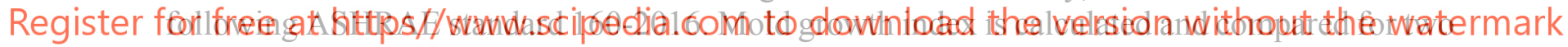
sensitivity classes: "Sensitive" class, corresponding to wood-based boards such as plywood and OSB, and "Very sensitive", usually used for untreated wood and used here as a worst-case scenario for mold growth potential. The mold growth index calculation uses hourly temperature and relative humidity data extracted from the simulations following the procedure prescribed in ASHRAE 160. The standard states that in order to minimize problems related to mold growth, the mold growth index should not exceed a value of three.

The maximum mold growth index over the simulation period is summarized in Table 1. The mold growth index is slightly higher for the assemblies with a VDP, in spite of the lower MC values on the sheathing. The explanation for this phenomenon is that during the beginning of the simulation there is a short period during which the $\mathrm{MC}$ and $\mathrm{RH}$ are rising quicker in the assemblies with a VDP, and therefore a higher maximum mold growth index in the VDP assemblies. Later in the simulation RH levels are lower in the assemblies with the VDPs and the difference in mold index reduces, but the 2-year simulation period is not enough to close the initial gap in mold index for most simulations. For the assemblies examined, no improvement in mold index was found, even though MC values did show improvement. According to ASHRAE 160 criteria, there is mold growth risks only when "very sensitive" class is assumed for both OSB and Plywood sheathed wall assemblies. 
Table 1. Maximum mold growth index over the simulation period.

\begin{tabular}{ccccccc}
\hline & \multicolumn{2}{c}{ Simulation inputs } & \multicolumn{2}{c}{ Mold index, Sensitive } & \multicolumn{2}{c}{ Mold index, Very sensitive } \\
\hline Sheathing & $\begin{array}{c}\text { Exterior } \\
\text { insulation }\end{array}$ & Orientation & without VDP & with VDP & without VDP & with VDP \\
\hline OSB & & East & 1.38 & 1.39 & 4.41 & 4.43 \\
\hline OSB & & South & 0.02 & 0.02 & 0.02 & 0.02 \\
\hline Plywood & & East & 1.00 & 1.12 & 3.47 & 3.84 \\
\hline OSB & Mineral wool & East & 0.03 & 0.07 & 0.11 & 0.21 \\
\hline
\end{tabular}

\section{Conclusions and Discussions}

Vapor diffusion ports have an ability to modestly improve the rate of drying for wall assemblies with an on-going moisture source of rain infiltration on the sheathing layer based on the hygrothermal simulations of this study. Table 2 summarizes the improvement due to VDP effects of MC (max and root mean square difference), mold index, and number of days to dry to under 20\% MC. The higher the MC of the assembly, the greater the potential contribution of the VDP to drying. For the East-oriented wall, the maximum MC difference in OSB sheathing is $3.85 \%$ with an average difference of $1.5 \%$, while for the south-oriented wall the maximum MC difference in OSB sheathing is $1 \%$ with an average difference of $0.4 \%$. Similar trend is found for plywood-sheathed wall. With the addition of exterior insulation, the temperature of sheathing is elevated and therefore improved drying capacity. Consequently, the contribution of VDP to drying is reduced. The provision of VDP also reduces the time for OSB sheathing to dry to below $20 \% \mathrm{MC}$. For example, an OSB sheathed wall with no exterior insulation oriented
to the east will take 22 less days to dry to under $20 \% \mathrm{MC}$ due to the presence of a VDP.
However, the effect of VDP on the mold growth risk is negligble.
Table 2. Summary of improvement in MC and mold index due to VDP effects (comparison between assomblies
with VDP and without VDP).

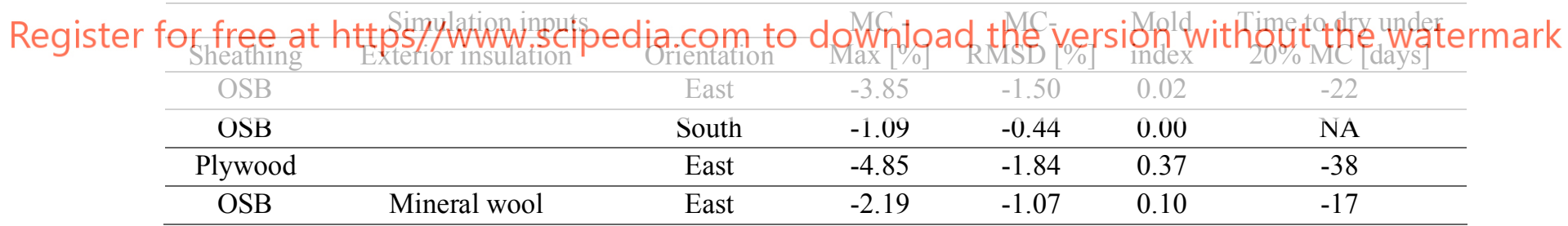

\section{ORCID}

Ben Zegen Reich: http://orcid.org/0000-0003-1192-499X

Hua Ge: http://orcid.org/0000-0003-1368-4301

Jieying Wang: http://orcid.org/0000-0002-0895-1797

\section{References}

ASHRAE Standard 160, Criteria for Moisture-Control Design Analysis in Buildings, ASHRAE, Atlanta, 2009 Hazleden, D. G. and Morris, P. I. (2001). Evaluation of Vapor Diffusion Ports on Drying of Wood-frame Walls under Controlled Conditions. Forintek Canada Corp. report for project 3134. Vancouver, BC.

Salonvaara, M., Zhang, J. and Karagiozis, K. (2011). Environmental Weather Loads for Hygrothermal Analysis and Design of Buildings. ASHRAE RP-1325. Simulation studies and data analysis.

Wang, J. (2018). Evaluation of Effects of Vapor Diffusion Ports on Drying Performance of Modern Wood-Frame Walls. FPInnovations report to Forestry Innovation Investment and the CFS, NRC. Vancouver, BC. 